Prof. N. V. Sidgwick had pointed out that the symmetric forms (IV) and (V) differ from the unsymmetric form (III) inasmuch as they possess the ring<smiles></smiles>

(vIII)

(VIII) and might be expected to have greater stability than the unsymmetric form (III). The chelated di-sulphide and di-arsine compounds (IX), (X) and (XI) have consequently been prepared by Chatt and Mann. If<smiles>[R]S[Y12](=S)Cl</smiles>

(Ix)<smiles>[R16][Y16]1([R16])CCCC1Cl</smiles>

(x)

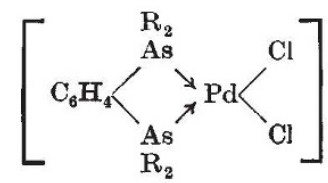

(XI)

these compounds reacted with ammonium palladochloride, the resulting 'bridged' compounds must have the unsymmetric structure of type (III). Actually no 'bridged' derivatives were obtained from these three compounds, and it appears therefore that the unsymmetric compounds are too unstable to exist in the solid state. On the other hand, Mellor, Burrows and Morris prepared two isomeric cuprocupric compounds, of formula $\left[\left(\mathrm{R}_{3} \mathrm{As}\right)_{3} \mathrm{Cu}_{2} \mathrm{Cl}_{3}\right]$, and suggested that these isomerides have the

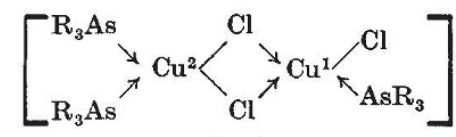

(xII)

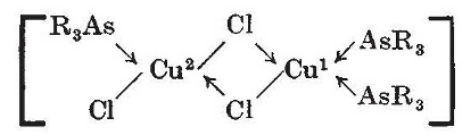

(XIII)

constitutions (XII) and (XIII), the cuprous and the cupric complexes having the tetrahedral and the uniplanar configuration respectively. The former compound possesses a ring structure electronically similar to that in (III), and decisive evidence for the structure of these isomerides would be of great interest. Reference was also made to the cuprous and argentous compounds $\left[\mathrm{R}_{3} \mathrm{As} \rightarrow \mathrm{CuI}\right]_{4}$ and $\left[\mathrm{R}_{3} \mathrm{As} \rightarrow \mathrm{AgI}\right]_{4}$ investigated by Mann, Wells and Purdie.

Prof. L. O. Brockway pointed out that investigations of the structure of organic derivatives of the noble metals now afford definite information with regard to the number and length of the bonds by which the metallic atom is linked to other groups, as well as the characteristic inter-bond angles; the number of such bonds is $2,4,5$ or 6 in the compounds of various metals. The 4-covalent metals in the copper and nickel groups have a planar configuration in the divalent state (for example, the above palladium compounds, the cupric and argentic picolinates, and the nickel, palladium and platinum aldoxime derivatives) and a tetrahedral configuration in other valency states (for example, $\left[\mathrm{Cu}\left(\mathrm{CH}_{3} \mathrm{CSNH}_{2}\right)_{4}\right] \mathrm{Cl}$, $\left.\mathrm{Ni}(\mathrm{CO})_{4},\left(\mathrm{CH}_{3}\right)_{3} \mathrm{PtCl}\right)$. The 2-covalent metallic complexes have a linear configuration (for example, $\left[\mathrm{Ag}(\mathrm{CN})_{2}\right]$ ), the 5-covalent a trigonal bipyramid (for example, $\left.\mathrm{Fe}(\mathrm{CO})_{5}\right)$ and the 6-covalent an octahedral configuration. He emphasized, however, that the work of Mann and Wells on the bridged palladium compounds shows that the co-ordinate and covalent links (as represented in the above formulæ) are identical in length, and that it is impossible to make a clear distinction between these links in complex metallic compounds. As an example of the variation of bond length with the number of bonds per atom, he cited the series $\mathrm{Ni}(\mathrm{CO})_{4}, \mathrm{Co}(\mathrm{NO})(\mathrm{CO})_{3}$, $\mathrm{Fe}(\mathrm{NO})_{2}(\mathrm{CO})_{2}, \mathrm{Cr}(\mathrm{CO})_{5}$. The metallic atoms in these compounds are isoelectronic, but whereas the observed bond-length to carbon in the first three compounds is 1.82-1.84 A., in the fourth compound it is $1.91 \mathrm{~A}$.

A very interesting example of the application of complex metallic compounds to the study of nuclear physics was given in a preliminary announcement by Dr. B. C. Saunders. Dr. Goldhaber and he have used the non-ionic cupric derivative of ethyl aceto-acetate to effect the separation of the active isotope of copper $\left({ }_{29}^{64} \mathrm{Cu}\right)$. The copper aceto-acetate is irradiated by slow neutrons and its activity measured : it is then dissolved in chloroform and shaken with aqueous copper acetate. Some of the active isotope is thus transferred to the aqueous solution, from which it is precipitated by zine, and its activity is measured. The chloroform layer gives copper acetoacetate of much reduced activity. F. G. MANN.

\title{
Recent Research in Seismology
}

$\mathrm{U}$ NDER the chairmanship of Dr. C. G. Darwin in the morning, and of Mr. R. S. Whipple in the afternoon of August 23, a symposium on seismology covering a very wide field of topics was held at Cambridge in Section A (Mathematics and Physical Sciences) of the British Association. At the outset, a very warm tribute was paid by Dr. F. J. W. Whipple to the pioneer work of Dr. C. Davison, who was the secretary of the earth tremors committee in 1895 , when Prof. John Milne returned to England from Japan. The work of these and others has led on to the present work on the International Seismological
Summary, now being carried on by Miss E. F. Bellamy and Mr. J. S. Hughes. There are now 439 observatories in the northern hemisphere and 59 in the southern hemisphere sending seismological readings to Oxford, from which it has been possible to locate 2,865 different epicentres between 1913 and 1935. It is hoped that more stations will be initiated in the southern hemisphere, especially in South America and South Africa.

In pure seismology, the discussion was continued by Miss I. Lehmann of Copenhagen, who described and explained the characteristic seismograms obtained 
on instruments at different epicentral distances, the differences being due to reflections and refractions of the various pulses in the interior of the earth. The suggestion by the late Prof. H. H. Turner of the occurrence of especially deep focus earthquakes had been confirmed by the work of Dr. R. Stoneley, Mr. F. J. Scrase and others, and this led Dr. H. Jeffreys to suggest that the hypothesis of Barrell was probably correct when he attributed finite strength to the earth down to a depth of about $700 \mathrm{~km}$. Further, the work of Dr. D. W. Phillips helps to explain the existence of aftershocks, in that it has been shown that rocks may possess several strengths according to the method of application and duration of the forces. The intensive study of deep focus earthquakes is likely to lead to solutions of some difficult seismological problems, including the depth of the core, the nature of the $20^{\circ}$ discontinuity, and the times of transmission of the transverse wave up to epicentral distances of about $25^{\circ}$.

In continuation, Dr. R. Stoneley showed that, as the result of considerable labour, Turner's readings of the $L$ phase of earthquakes corresponding to $0.48 \mathrm{~min}$./degree could be identified with long Rayleigh waves, and that the readings corresponding to $0.41 \mathrm{~min}$./degree could be assigned to the arrival of long waves first theoretically predicted by Prof. A. E. H. Love. The former are usually designated $L R$ waves and the latter $L Q$ waves. It is suggested that the difference between these two types of waves is due to differences at the origin. $L Q$ and $L R$ are well separated at distances greater than $50^{\circ}$.

Of interest to pure seismology is the work of Prof. J. D. Bernal, who concludes that there may be, at the pressures and temperatures existing at some depth within the earth, a denser and less compressible form of olivine, $(\mathrm{MgFe})_{2} \mathrm{SiO}_{4}$, than occurs normally on the surface. This would possibly explain the $20^{\circ}$ discontinuity. Crystallography should also be considered when discussing the structure of the earth's core.

Interesting on account of its application to both pure and applied seismology is the work of Dr. D. W. Phillips, who described experiments he has performed in compression, bending and torsion on coal measure sandstones, siltstones, mudstones, shales and coals, and also on some samples of marble. These experiments show up very clearly the imperfect elasticity of the rocks, which behave as perfectly elastic under stresses applied for a short time, but give 'hysteresis loops', possibly with complete recovery only after a very long time, when a stress is applied for a longer time. An interesting phenomenon found is that a stress large enough to give irrecoverable deformation may at first give only continuous deformation and yet lead to fracture if it is maintained long enough. Dr. Jeffreys showed later how this may account for the occurrence of continuous folding and fracture in the same arch, a common geological phenomenon. The fracture would cause an earthquake.

In the realm of applied seismology, Mr. T. F. Gaskell described the method of working and the results of the work of Dr. Bullard and himself. The method is to fire a small amount of gelignite and record automatically the seismic waves set up, by means of geophones at $200 \mathrm{ft}$. intervals up to $1,000 \mathrm{ft}$. , recording the initial time of the shock by a radio signal. From the resulting seismograms the shape of the palæozoic floor of part of eastern England has been determined, the process being facilitated by the fact that the wave velocities in the palæozoic rocks are high, whilst those in the chalk and overlying strata are low.

\section{Educational Significance of the Cinema and Wireless}

\begin{abstract}
A JOINT discussion at Cambridge on August 23 A between Section $J$ (Psychology) and Section L (Educational Science) on the cinema and wireless in education was opened by Mr. R. C. Steele, who dealt mainly with broadcasting.

Pointing out the remarkable growth in the use of broadcast methods since they were first introduced in schools fifteen years ago, especially in the last two years, Mr. Steele referred to the difficulty of evaluating their effects. He suggested that with dull or backward children the broadeast lesson is probably more effective in proportion to their ability than with the brighter pupils. It also offers a change from ordinary routine, presenting new material in a new and vivid way, which appeals to the imagination. $\mathrm{He}$ considers that with the backward child it is a further advantage that the broadcaster, though he may ask questions, does not expect answers, and the dull child may thus gain confidence instead of being made conscious of inferiority to others. Mr. Steele stressed the importance of personality and, discussing the use which could be made of broadcasting in education, suggested that where detail is of prime importance, as in a science lesson, the film is likely to be supreme. Where perfection of detail is less important and immediacy is the first consideration,
\end{abstract}

broadcasting and television may give the best results, and he predicted a great future for television in school teaching.

Mr. Steele's paper was supplemented by a paper by Miss L. M. Holt giving some statistical results of tests made with children who had been having wireless and ordinary lessons alternately, which were designed to determine the characteristic contributions of this new aid to teaching. The spontaneous contrasting of the facts in their possession was slightly higher in essays based on wireless lessons than in essays based on oral lessons, while a fine perception of specific or significant detail also characterized the wireless essays, indicating a good grasp of the subject.

Dr. P. B. Ballard, discussing the effect of wireless and the einema on the life of the school child, emphasized the experimental nature of the educational film as part of the school programme. It cannot be assumed that the child always prefers a talking to a silent film. There is direct evidence to the contrary, and for educational purposes the evidence indicates that the film should be short-for example, five to ten minutes - and unless the commentator speaks slowly and clearly and in simplified language appropriate to the audience, a silent film 